\title{
Assessment of factors influencing surface recrystallization during high temperature exposure of fine grained PM 2000 alloy
}

\author{
J.L. González-Carrasco a,", J. Chao ${ }^{\mathrm{a}}$, C. Capdevila ${ }^{\mathrm{a}}$, J.A. Jiméneza, V. Amigó ${ }^{\mathrm{b}}$, and \\ M.D. Salvador ${ }^{\mathrm{b}}$ \\ ${ }^{a}$ Centro Nacional de Investigaciones Metalúrgicas (CENIM-CSIC), Avenida Gregorio \\ del Amo no8. 28040 Madrid, Spain \\ b Instituto de Tecnología de Materiales de la Universidad Politécnica de Valencia, \\ Camino de Vera, s/n. 46022 Valencia, Spain \\ * Corresponding author. Tel.: +34 91 5538900; fax: +34 915347425. Email address: \\ jlg@cenim.csic.es
}

\begin{abstract}
PM 2000 offers an excellent oxidation resistance that relies on the capability to develop during service an $\alpha$-alumina scale, fine, but tightly adhered to the substrate. Advantages of the scale protection at low temperatures are obtained by performing a pre-oxidation treatment prior to operation. Due to the high temperatures involved in the preoxidation treatment microstructural stability of the alloy could be affected. The aim of this study is to characterise the microstructural changes during oxidation $\left(1100^{\circ} \mathrm{C} / 120 \mathrm{~h}\right)$ of the alloy in a fine grained state that is more suitable for room temperature applications. Special emphasis is devoted to the analysis of zones beneath the scale where tensile and fatigue fractures are usually initiated. It is interesting to remark that beneath the oxide scale grain growth occurs forming a shell of about 10 microns of coarse grains.

Microtexture analysis performed at these zones reveals that population of grains with a $\{111\}$ texture decreases towards the centre of the sample. The results presented in this work clearly confirms that recrystallization is not related to oxidation-induced effects but to the heterogeneous deformation produced during machining, that stimulate recrystallization to occur at much lower temperatures.
\end{abstract}

Keywords: Recrystallization; ODS alloys; oxidation; texture analysis 


\section{Introduction}

The PM 2000 is an iron-base oxide dispersion strengthened (ODS) superalloy manufactured by a complex powder metallurgy route. In a first step, a mixture of metallic powders and dispersoids are mechanically alloyed to produce a final powder in which a fine dispersion of yttrium oxide particles is formed. Resulting powders are then canned and hot extruded and/or hot rolled. The microstructure at this stage presents submicron-sized elongated grains similar to that found in cold deformed materials [1]. A subsequent recrystallization treatment at very high temperature $\left(>1300^{\circ} \mathrm{C}\right)$ yields a coarse microstructure with strongly elongated grains parallel to the extrusion direction, which is more suitable for high temperature applications.

Particularly attractive is the excellent oxidation resistance of the alloy that relies on the capability to develop a compact and adherent $\alpha-\mathrm{Al}_{2} \mathrm{O}_{3}$ scale at high temperature. During oxidation different transient alumina states can be form, which are known to grow faster than $\alpha$-alumina [2]. The transformation of metastable alumina phases into $\alpha$ $\mathrm{Al}_{2} \mathrm{O}_{3}$, by thermo dynamical definition, is an irreversible phenomenon that depends on exposure time and temperature, being the metastable- $\alpha$ transition temperature around $1000^{\circ} \mathrm{C}[3]$. Obviously, the higher the temperature the faster this transformation processes. If the alloy is to be used either at lower temperatures or under low-oxygen partial pressure environments, it has to be "pre-oxidised" at high temperature in pure oxygen or in air to develop the $\alpha-\mathrm{Al}_{2} \mathrm{O}_{3}$ scale prior to operation.

Beneficial effects of a pre-oxidation treatment have been mainly addressed for coal gasification environments at intermediate temperatures [4-6] but this treatment can be also beneficial for other new applications at low temperatures. For example, it has been proposed that ferritic alloys could be promising candidates for surgical implants [79] because they combine the good mechanical properties of the metal substrate with the protective capacity of the alumina scale against physiological solutions [10]. The main limitation when using ferritic alloys at ambient temperature is that, as any BCC material, they exhibit a ductile-brittle transition (DBT) at around room temperature [11]. DBT temperature is related with the grain size, and to decrease this value a fine grain microstructure is required [12]. Therefore, pre-oxidation temperatures should be as low as possible to avoid the substrate recrystallization. An optimum temperature for thermal oxidation of $1100{ }^{\circ} \mathrm{C}$ was selected since it yields to a $\alpha$-alumina layer with a few 
microns in thickness within

reasonable production times. The analysis of

the tensile and fatigue behaviour of pre-oxidised PM2000 [8] led to the consideration that this pre-oxidation temperature did not jeopardize the good mechanical properties of the fine-grained material. Moreover, toughness tests of specimens with and without scale indicated a significant increase of the impact energy for the pre-oxidised specimens [13], which is contrary to the expected embrittlement induced by the scale $[12,14-16]$. As tensile and fatigue fractures are initiated beneath the scale $[12,8]$, this study is aimed to characterize the microstructural changes during high temperature oxidation, with special emphasis at the zones near to the scale-metal interphase. Since the crystallographic orientation of grains could be of great importance for most mechanical properties [17], texture change was also locally investigated by using EBSD techniques.

\section{Experimental part}

The PM2000 alloy, nominally Fe- 20Cr- 5.5Al- 0.5Ti- 0.5 Y203 (wt pct), was prepared at Plansee GmbH (Lechbruck, Germany) by mechanical alloying of a mixture of metallic powders and dispersoids, and further consolidation to obtain a hot rolled bar of $35 \mathrm{~mm}$ in diameter. Fatigue specimens were machined from cylinders taken at equivalent positions with respect to the centre of the bar. Therefore, the influence of differences in the gradient of deformation and the associated residual stresses, if any, is not expected. After machining, surface of the fatigue specimens was abraded with silicon papers to eliminate severe scratches. Specimens were finally washed in running water and then cleaned with alcohol. Preoxidation was performed at $1100^{\circ} \mathrm{C}$ for 120 hours in air. Results of fatigue behaviour of specimens with and without scale have been published in previous works $[8,18]$.

Microstructural investigations in the present work were performed on samples sectioned from heads of broken fatigue specimens. Conventional metallographic techniques and scanning electron microscopy (SEM) using a JEOL JSM 6500F were used for this goal. Backscattered electron images (BEI) of polished and etched samples were used to determine the grain size. Texture measurements in the as-received and annealed $\left(1100^{\circ} \mathrm{C} / 120 \mathrm{~h}\right)$ conditions were performed in the back-reflected mode by XRay diffraction using a X-ray difractometer set-up with HI-STAR two dimensional multiwire proportional counter (General Area Detector Diffraction System, Bruker AXS). Co $\mathrm{K}_{\alpha}$ radiation was employed at a tube current of $30 \mathrm{~mA}$ and a voltage of 40 
Page 4 of 12

$\mathrm{KV}$. The detector was centered at

$2 \theta=52.40^{\circ}, 77.20^{\circ}$ and $99.70^{\circ}$, with the center

of the detector $2 \theta$ position coupled with the beam's incident angle $\theta$. At each $2 \theta$

position enough planar frames were collected for covering the entire pole sphere. From the normalized and corrected X-ray data, the (110), (200)) and (211) pole figures were reconstructed. The sample reference system was fiber, corresponding to the symmetry imposed by the hot rolling process. From these pole figures it was calculated the orientation distribution function (ODF) using the series expansion method $(1 \max =22)$ and ghost corrected. As ferrite present cubic symmetry, the orientation density, $\mathrm{f}(\mathrm{g})$, was represented in the reduced Euler space $\left(0 \leq \varphi_{1}, \Phi, \varphi_{2} \leq \Pi / 2\right)$. The samples for texture analysis were cut perpendicular to the longitudinal bar direction. These samples were grinded and fine mechanically polished with 1 micron diamond paste and colloidal silica $(40 \mathrm{~nm})$ to remove the deformed layer.

Microtexture analysis of pre-oxidised specimens was performed by the Electron Backscattering Diffraction (EBSD) technique. EBSD patterns were collected at various locations on cross sections carefully polished with colloidal silica in the final phase. The EBSD patterns were generated at an acceleration voltage of $20 \mathrm{KV}$ and collected using a CRYSTAL detector of Oxford Instruments mounted in a SEM JEOL JSM6300. The indexation of the Kikuchi lines and the determination of the orientations were done with the software INCA developed by Oxford Instruments. The results were represented by means of an inverse pole figure (IPF) maps, which give the orientation of a macroscopic direction with respect to a specific crystal direction.

\section{Results and discussion}

Longitudinal and transverse sectioned samples of as-received bar revealed a fine grained structure with a mean value of about $2 \mu \mathrm{m}$ in diameter. These grains appear slightly elongated along the longitudinal bar direction. This microstructure was homogeneous over the bar thickness. Texture analysis through the pole figures, Fig.1, reveals a weak fiber texture, about 1.4 times random, with the $<110>$ direction parallel to the rolling direction, i.e. the (110) plane is perpendicular to the bar axis. This texture is typical of BCC materials deformed by either extrusion or rolling. The absence of a strong texture is confirmed by analysis of an ODF section at $45^{\circ}$ in $\varphi_{2}$, Fig.2, which in the case of BCC materials include most of the texture components. As can be seen, the typical $\alpha\left(\right.$ at $\left.\varphi_{1}=0\right)$ and $\gamma$ components $\left(\right.$ at $\left.\Phi=55^{\circ}\right)$ of hot rolled products are absent, been only visible a weak fiber characterized by the $<110>$ direction parallel to the 
Page 5 of 12

rolling axis. The component of

this fiber are located at the line of $\Phi=90^{\circ}$ (top of Fig.2) and present an orientation density nearly constant from 0 to $90^{\circ}$ in $\varphi_{1}$.

A continuous alumina scale was formed during high temperature oxidation $\left(1100^{\circ} \mathrm{C} / 120 \mathrm{~h}\right) . \mathrm{SEM}$ examination of the sample surface revealed the presence of oxide nodules with a submicron size, Fig. 3a, although in a few cases they can reach one micron. A cross sectional micrograph (Fig. 3b) reveals an even alumina scale, with a thickness of about 4 micron, which is consistent with the temperature and exposure times used for pre-oxidation [9]. Figure $3 \mathrm{~b}$ shows also the presence of a shell of coarser grains with an average thickness of about 10 microns beneath the oxide scale grain that indicates a local grain growth in this zone during oxidation. Occasionally, the coarse grained zone can be wider, and a maximum width of about 500 microns was measured. The rest of the substrate material only reveals a moderated grain size increase, which is macroscopically manifested by a decrease in hardness and $0.2 \%$ yield strength [8]. As a consequence of the grain structure stability during oxidation no appreciable change in the texture from the starting condition was observed.

Fig. 4 shows an inverse pole figure color map of a sample after oxidation. The correspondence between the color of the different grains and the crystallographic orientation is indicated in the stereographic triangle. This figure reveals that the population of grains with a $\{111\}$ texture is high near the surface and decreases towards the centre of the sample. Normalised distributions of misorientation angles obtained from single orientation measurements made by EBSD are shown in Fig. 5. As can be seen, the distributions of misorientation angles were virtually constant over the bar thickness. A high fraction of high angle boundaries is observed.

A local grain growth beneath the alumina scale has been reported for the PM ODS alloys Fe40AlGrade 3 [19] and sandblasted MA 956 during a preoxidation treatment preformed at $1100^{\circ} \mathrm{C}$. In the present investigation, it has been proved that oxidation at this temperature yields beneath the scale not only to a local grain growth but also to a change in the grain orientation. Both results confirm that a true recrystallization process took place during the preoxidation treatment in this zone. In principle, this feature is somewhat unexpected since for ODS alloys recrystallization occurs at exceptionally high homologous temperatures, in this alloy about $0.9 \mathrm{Tm}$, were $\mathrm{Tm}$ is the melting temperature of $1487^{\circ} \mathrm{C}$.

Since the texture components of the recrystallized grains are similar to those obtained after a recrystallization treatment at higher homologous temperatures [20] it 
could be concluded that the mechanism of recrystallization should be similar in both cases. Several mechanisms have been proposed to explain the high recrystallization temperature $\left(T_{R}\right)$ in the range $1300-1450{ }^{\circ} \mathrm{C}$. It has been speculated [21] that solute-drag limits grain boundary mobility until a temperature is reached, where the solute atmosphere evaporates. The idea is inconsistent with the observations that the recrystallization temperature can be greatly reduced by certain processing as it will be discussed below [22,23]. Besides, solute-drag is a feature of all commercial alloys which are impure so it is hard to see why the mechanically alloyed ODS alloys should show exceptional behaviour. In other work [24] it has been suggested that particles of yttrium oxide or various yttria/alumina compounds (spinels) must coarsen before recrystallization can occur. However, the limiting grain size is in fact very large. Furthermore, $T_{R}$ is found to be insensitive to changes in the particle pinning force.

The difficulties are resolved as follows. The nucleation of recrystallization in the present context begins by the bowing of a grain boundary. This normally is straightforward because the size of the boundary perturbation is small when compared with the grain size. However, with very small grains, the boundary junctions themselves act as severe pinning lines restricting bowing (Fig. 6). This leads to an enormous activation energy $Q$ for the nucleation of recrystallization, ten times larger than $Q_{D}$ that is the activation energy for self diffusion [25]. Q is reduced if a few grains happen to be larger; indeed, any non-uniformity introduced into the microstructure, for example by inhomogeneous deformation, will lead to a large decrease in $T_{R}$ [26]. This model suggests that the individual grains cannot be considered to be topologically independent when the grain size becomes small. It explains the observed high values of $T_{R}$ that are independent of alloy type; the common feature of the iron and nickel base alloys is the fine grain structure following the mechanical alloying process.

The most important question that arose in this investigation is why the recrystallization temperature drops near the scale - matrix interface. As it was pointed out by Capdevila and Bhadeshia [27], for reasons which are not obvious, recrystallization seems easiest whenever the $\{111\}<-110>$ is prominent. In this sense, it was reported that MA956 prior to recrystallization is rich in this particular component whereas MA957 is not, probably due to the presence of austenite in MA957 at the fabrication temperature [28]. The former has a lower $T_{R}$ compared with the latter, even though MA957 has a higher stored energy and lower yttria content than MA956.

However, if MA957 is pre-annealed (i.e. heat-treated without recrystallization) in order to make its texture comparable to that of MA956, then its recrystallisation temperature 

treatment. An additional important feature has to be considered to understand the recrystallization mechanism in PM2000. As was reported by Regle and Alamo [29], which have conducted extensive studies on the recrystallization behaviour of cold deformed MA956 and MA957 samples, deformation led to a reduction in the recrystallization temperature. For MA957, the maximum reduction in the recrystallization temperature was found to be about $200^{\circ} \mathrm{C}$ from $1450 \rightarrow 1250{ }^{\circ} \mathrm{C}$. The corresponding maximum reduction was for MA956 samples, where the recrystallization temperature could be reduced from $1350 \rightarrow 750{ }^{\circ} \mathrm{C}$.

Chou [30] has measured the stored energies in the samples studied by Regle and Alamo[29]. Surprisingly, he found no increase in stored energy with deformation; indeed, it appears that the deformation leads to a reduction in stored energy. He concluded that the cold deformation modifies the crystallographic texture. It is conceivable that the texture change both leads to a reduction in the stored energy, and at the same time, a reduction in the recrystallization temperature. The texture could, for example, lead to the clustering of adjacent grains into similar orientations. This would lead to an increase in the effective grain size, thereby making the nucleation of recrystallization easier. This results is consistent with the above mentioned enhance of recrystallization (an hence a subsequent drop of $\mathrm{T}_{\mathrm{R}}$ ) when $\{111\}$ texture is prominent, and therefore with the texture measurements obtained by EBSD and shown in Fig. 4.

There are some other results presented by Capdevila and Bhadeshia [31] that are consistent with this interpretation. A sample that was deformed by bending (and hence contained a controlled deformation gradient) was subjected to a recrystallization heat treatment. After this treatment it was observed an anisotropic recrystallization grain structure and the grain refinement was related with the extent of deformation. Thus, deformation must enhance the nucleation rate of recrystallization, perhaps by the texture mechanism discussed above.

With regards to the role of the oxidation process on the surface recrystallization, it could be argued that inwards alumina scale growth during high temperature oxidation [2] causes a volume increase at the scale/metal interface, yielding to a local plastic deformation of the substrate. The phenomena is easily revealed by the presence of imprints beneath the scale, clearly visible at places where detachment of the scale has occurred [12]. In order to clarify if this recrystallization process is related with the deformation induced by the growth of the oxide layer, a set of specimens with three 
different surface conditions were pre-oxidised at $1100^{\circ} \mathrm{C}$, namely: as-grinded, asgrinded plus polished, and as-polished plus acid etching. The as-grinded condition is expected to retain a thin layer of heavily deformed material whereas polished and etched surfaces should hardly show any microstructural change. A close sectional examination by SEM revealed that only the grinded and oxidised surface contains a subscale layer of larger grains (Fig. 7). This clearly confirms that recrystallization of oxidised samples is not related to oxidation-induced effects but to the heterogeneous deformation produced during machining. Strain heterogeneities in the microstructure have been found to promote the nucleation of recrystallization, stimulating recrystallization to occur at much lower temperatures [32].

The microstructural evolution beneath the scale during oxidation should be taken into consideration for applications of fine-grained PM 2000 where surface related mechanical properties are important. This feature obviously will be obviously relevant for the mechanical behaviour of very thin components.

\section{4- Conclusions}

This paper analyzes the microstructural changes produced in the vicinity of the $\alpha$ $\mathrm{A} 12 \mathrm{O} 3$ scale - matrix interface during the pre-oxidation treatment. It can be concluded that the shell of recrystallized grains formed at the $\alpha-\mathrm{Al}_{2} \mathrm{O}_{3}$ scale - matrix interface of oxidised samples is not related to oxidation induced effects but to the heterogeneous deformation produced during machining. This result provides additional evidence about how strain heterogeneities in the microstructure promote the nucleation of recrystallization, stimulating recrystallization to occur at much lower temperature.

On the other hand, EBSD study of crystallographic orientations of both recrystallized grains themselves and unrecrystallized grains in their vicinity that deformation during machining induce a $\{111\}$ texture which, as it has been reported by several authors, enhance nucleation of recrystallization.

The results presented in this work are additional evidences about how strain heterogeneities in the microstructure promote the nucleation of recrystallization, stimulating recrystallization to occur at much lower temperature.

\section{References}

[1] E.A. Little, D.J. Mazey and W. Hanks, Scripta Metall. Mater. 25 (1991) 1115-1118 
[2] K.M.N. Prasanna, A.S. Khanna, Ramesh Chandra, and W.J. Quadakkers, Oxid. Met. 46(5/6) (1996) 465-480

[3] J. Doychak and M. Rühle. Oxid. Met. 31 (1989) 431-452

[4] V. Guttmann, A. Mediavilla and O. Ruano, Mater. High Temp. 11 (1993) 42-50.

[5] M. Lloyd: Proc. Frontiers of High Temperature Materials II, London, 1983, pp. 419441.

[6] P.S. Sidky and M.G. Hocking, Corros. Sci. 29 (1989) 735-765.

[7] M.L. Escudero and J.L. González-Carrasco, Biomaterials 15 (1994) 1175- 1180.

[8] J.L. González-Carrasco, G. Ciapetti, M.A. Montealegre, S. Pagani, J. Chao, and N. Baldini, Biomaterials 26(2005) 3861-3871.

[9] G. Strehl , J.L. González-Carrasco, J.L. Peris, M.A. Montealegre, S. García, C. Atienza, and G. Borchardt, Surf. Coat. Tech., in press 2006

[10] J.L. González-Carrasco, M.C. García-Alonso, M.A. Montealegre, M.L. Escudero, and J. Chao, Oxid. Met. 55 (2001) 209-221.

[11] J.M. Davidson, Frontiers of High Temperature Materials II, Proc. of the Second Int. Conf. on ODS Superalloys by Mechanical alloying. Edited by J.S. Benjamin and R.C. Been, IncoMAP. London. 1983, 163.

[12] J. Chao, J.L. González-Carrasco, J. Ibañez, M.L. Escudero, and G. GonzálezDoncel, Metall. Mater. Trans. 27A (1996) 3809-3816.

[13] J.Chao, unpublished results

[14] J.M. Davidson: Proc. Frontiers of High Temperature Materials II, London, 1983, pp. 163-189.

[15] T. Hughes and T. Hirst: Proc. Frontiers of High Temperature Materials II, London, 1983, pp. 149-162. 
[16] J.M. Davidson, C.M.

Trans.14A (1983) 1516-1518.

[17] J. Chao, M.C. Cristina, J.L. González-Carrasco and G. González-Doncel, Proc. Conf. "Materials for Advanced Power Engineering 1998”, Part II. Edited by L. Lecomte-Beckers, F. Schubert and P.J. Ennis. 1998. Forschungszentrum Jülich GmbH. p. 827.

[18] J. Chao, J.L. González-Carrasco, C. Capdevila, submitted to Mater. Sci. Eng. A (2006)

[19] J. Chao, D.G. Morris, M.A. Muñoz.Morris, and J.L. González-Carrasco, Intermetallics 9 (2001) 299-308.

[20] C. Capdevila, Y.L. Chen, N.C.K. Lassen, H.K.D.H. Bhadeshia and A.R. Jones, Mater. Sci. Tech. Ser. 17 (2001) 693-699.

[21] P. Jongenburger, Ph.D. Thesis no. 773, Ecole Polytechnique Federale de Lausanne, Switzerland, 1988.

[22] A. Alamo, H. Regle and J.L. Bechade, in Advances in Powder Metallurgy and Particulate Materials - 1992, Metal Powder Industries Federation, Princeton, NJ, USA, 1992, 169.

[23] C. Capdevila, Y.L. Chen, A. R. Jones and H.K.D.H. Bhadeshia, in Proc. of the 21st Riso International Symposium on Materials Science (Eds: N. Hansen, X. Huang, D. Juul Jensen, E. M. Lauridsen, T. Leffers, W. Pantleon, T. J. Sabin and J. A. Wert), Riso National Laboratory, Denmark, 2000, 271.

[24] M. Murakami, K., Mino, H. Harada and H.K.D.H. Bhadeshia, Metall. Trans. A, 24A (1993) 1049-

[25] W. Sha, and H.K.D.H. Bhadeshia, Mat. Sci. Eng. A 223 (1997) 91-98

[26] C. Capdevila and H.K.D.H Bhadeshia, Materials Algorithm MAP, www.msm.cam.ac.uk/map/steel/programs/tr_model.html

[27] C. Capdevila and H.K.D.H. Bhadeshia, Advanced Engineering Materials 3 (2001) 647-656.

[28] T.S. Chou and H.K.D.H. Bhadeshia, Mater SciTech 9 (1993) 890-897 
[29] H. Regle and A. Alamo,

Journal de Physiqe IV , 3 C7, 1993, 727.

[30] T.S. Chou, Ph.D. Thesis, University of Cambridge, U.K., 1994.

[31] C. Capdevila, Y.L. Chen, A.R. Jones and H.K.D.H. Bhadeshia, in Proc. of the 21st Riso International Symposium on Materials Science (Eds: N. Hansen, X. Huang, D. Juul Jensen, E. M. Lauridsen, T. Leffers, W. Pantleon, T. J. Sabin and J. A. Wert), Riso National Laboratory, Denmark, 2000, 277.

[32] C. Capdevila, U. Miller, H. Jelenak, H.K.D.H. Bhadeshia, Mater. Sci. Eng. A316 (2001) 161-165. 
Figure 1. (110) pole figure of PM 2000 in the as-hot rolled condition Figure 2 ODF figure at $\mathbf{4 5}^{\circ}$

Figure 3.- (a) Oxide nodules decorating the outer part of the alumina layer obtained during pre-oxidation heat treatment. (b) Shell of coarser grains in the interface between alumina scale and the matrix.

Figure 4.- EBSD image of recrystallised grains on the scale - matrix interface.

Figure 5.- Normalised distributions of misorientation obtained by EBSD.

Figure 6.- Grain boundary bulging leading to the nucleation of recrystallisation can occur readily when the grain junctions are widely spaced, at distances greater than the critical bulge size. With sufficiently fine grains in the unrecrystallised microstructure, the grain junctions themselves are pinning points, making it very difficult to form recrystallisation nuclei.

Figure 7 SEI images of specimens oxidised at $1100^{\circ} \mathrm{C} / 120 \mathrm{~h}$ after A) grinding and B) polishing/acid etching 


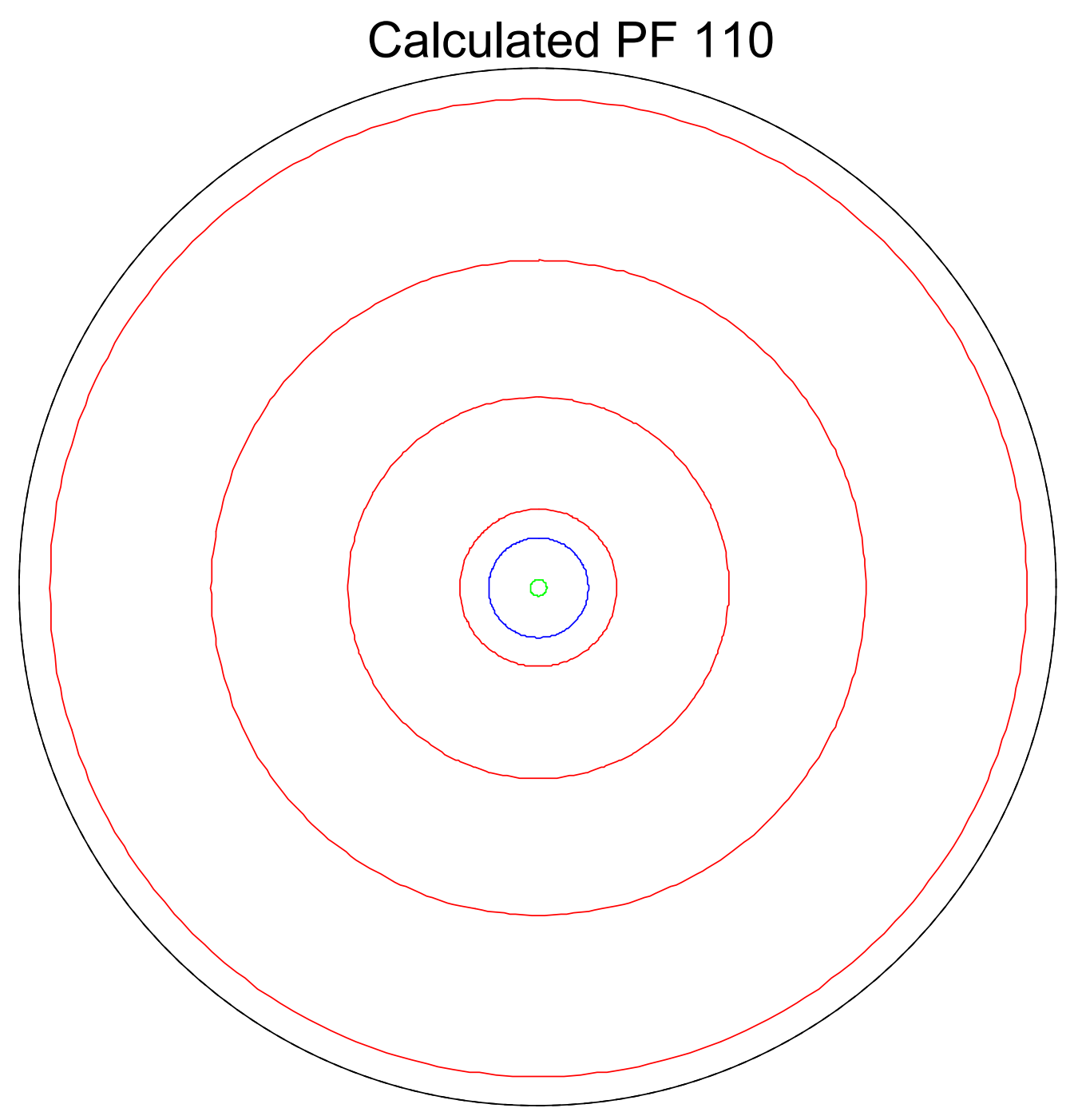

\begin{tabular}{ll}
- & 0.80 \\
0 & 1.00 \\
\hline & 1.20 \\
\hline & 1.40 \\
0 & 1.60
\end{tabular} 
Click here to download high resolution image

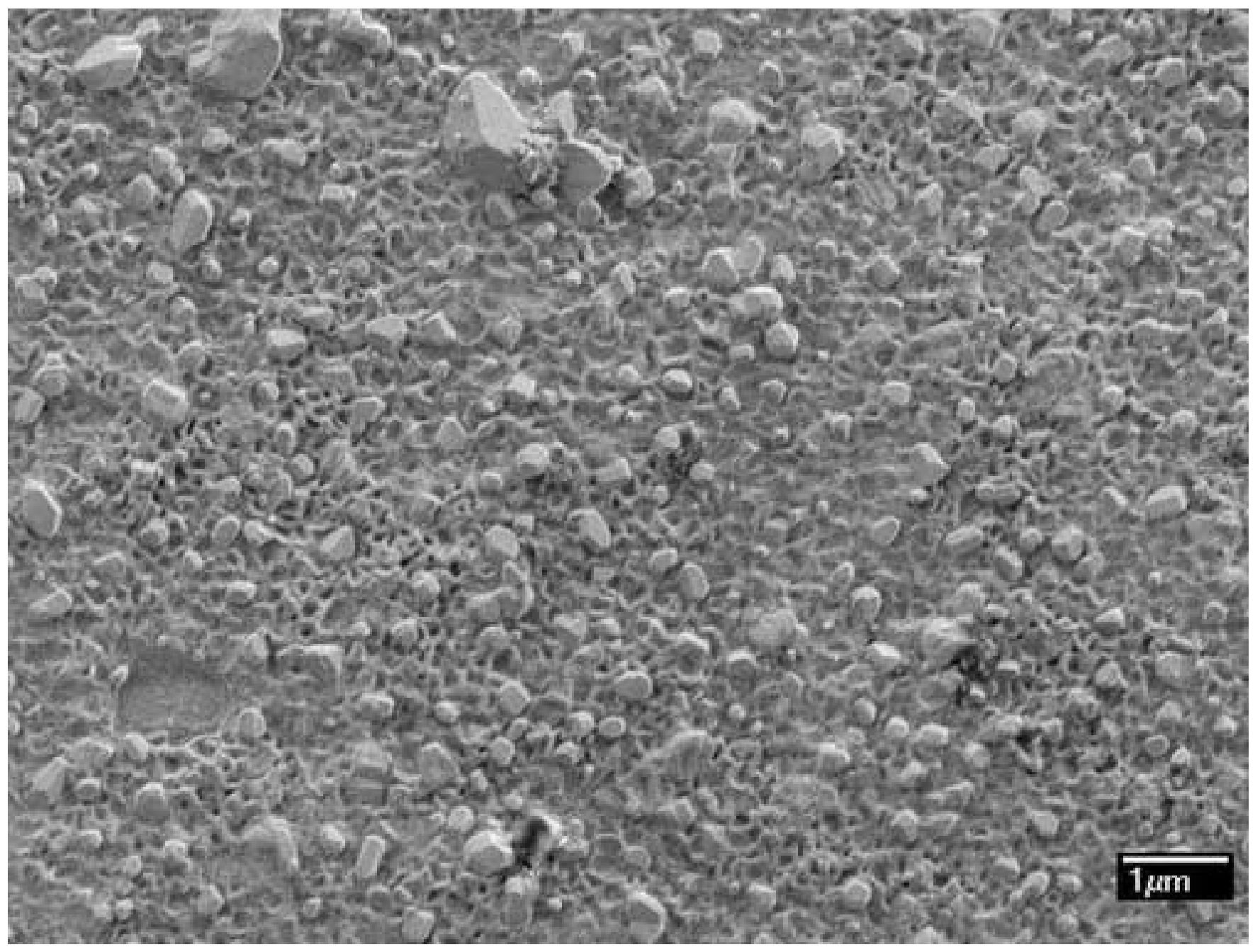

Figure(s)

\section{ck here to download high resolution image}

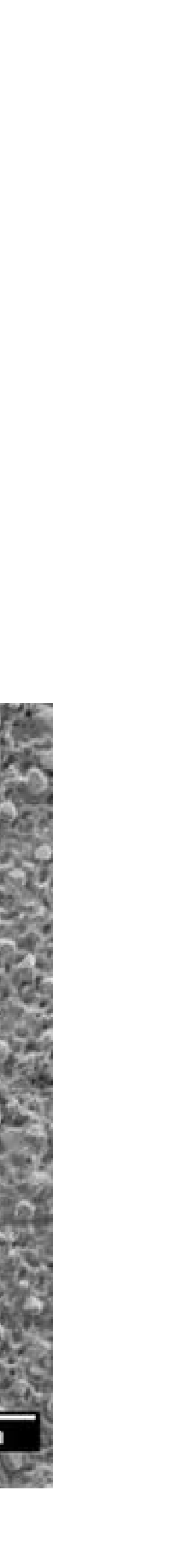


Figure(s)

Click here to download high resolution image

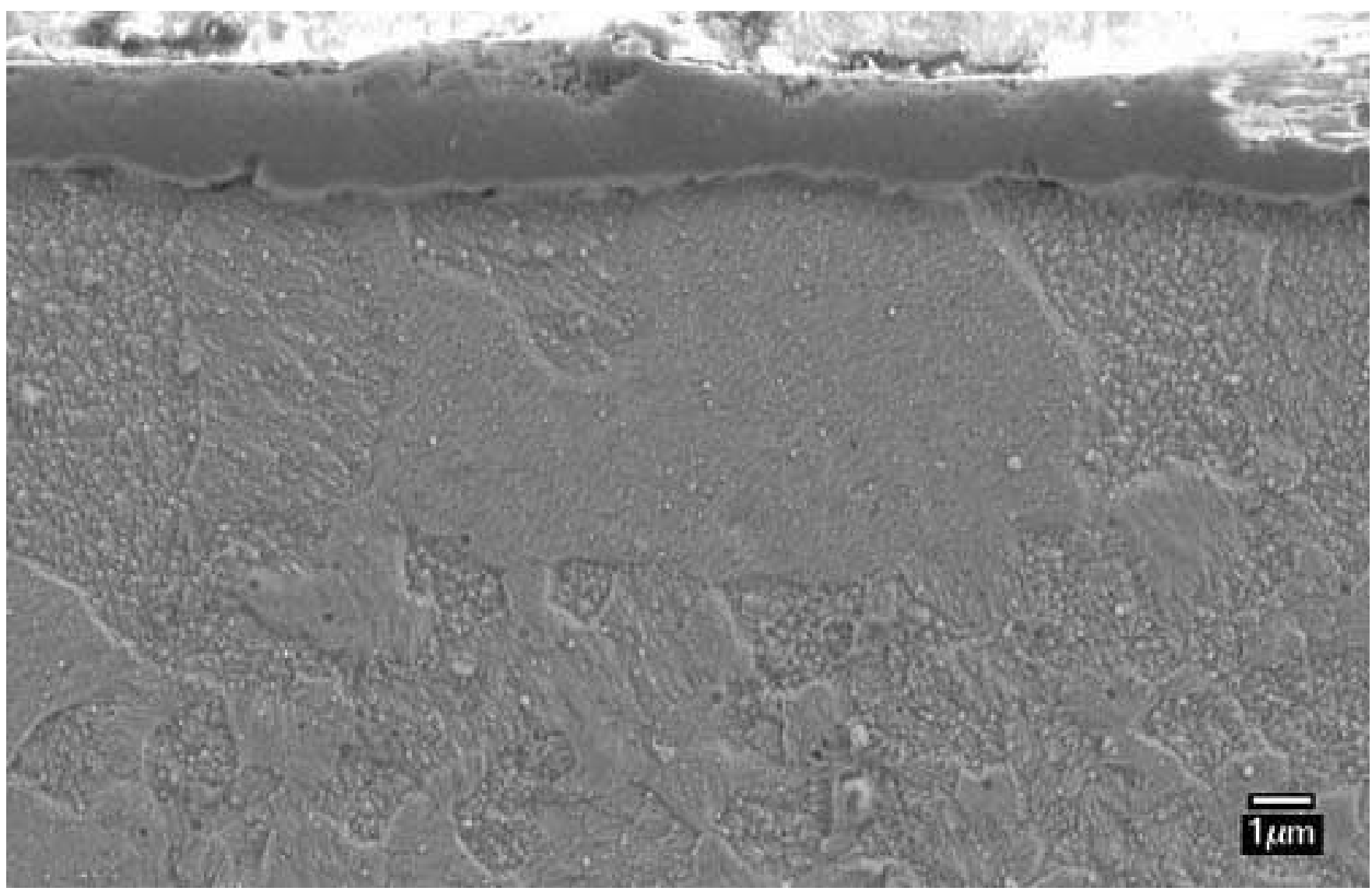


Figure(s)
Click here to download high resolution image
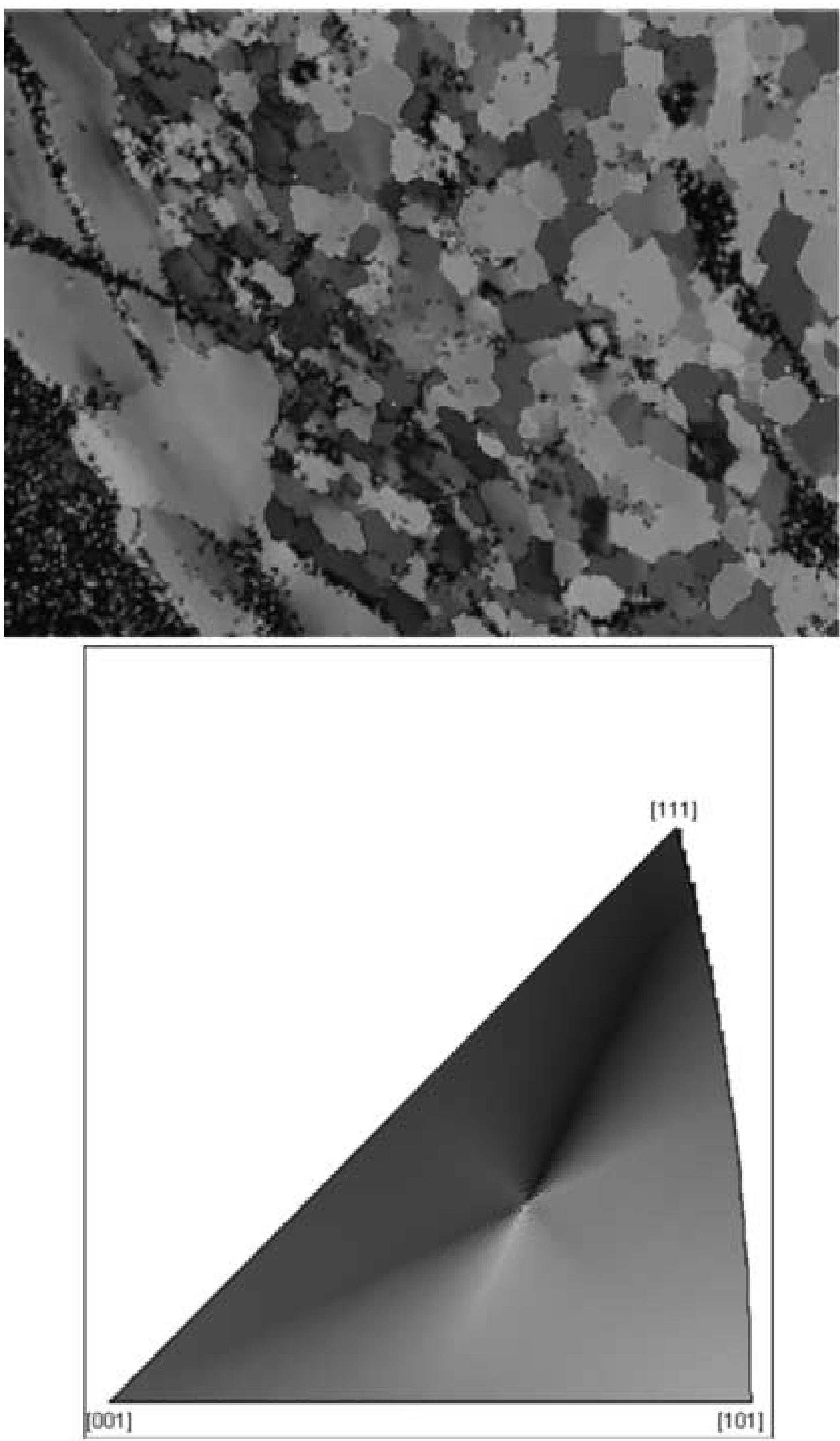

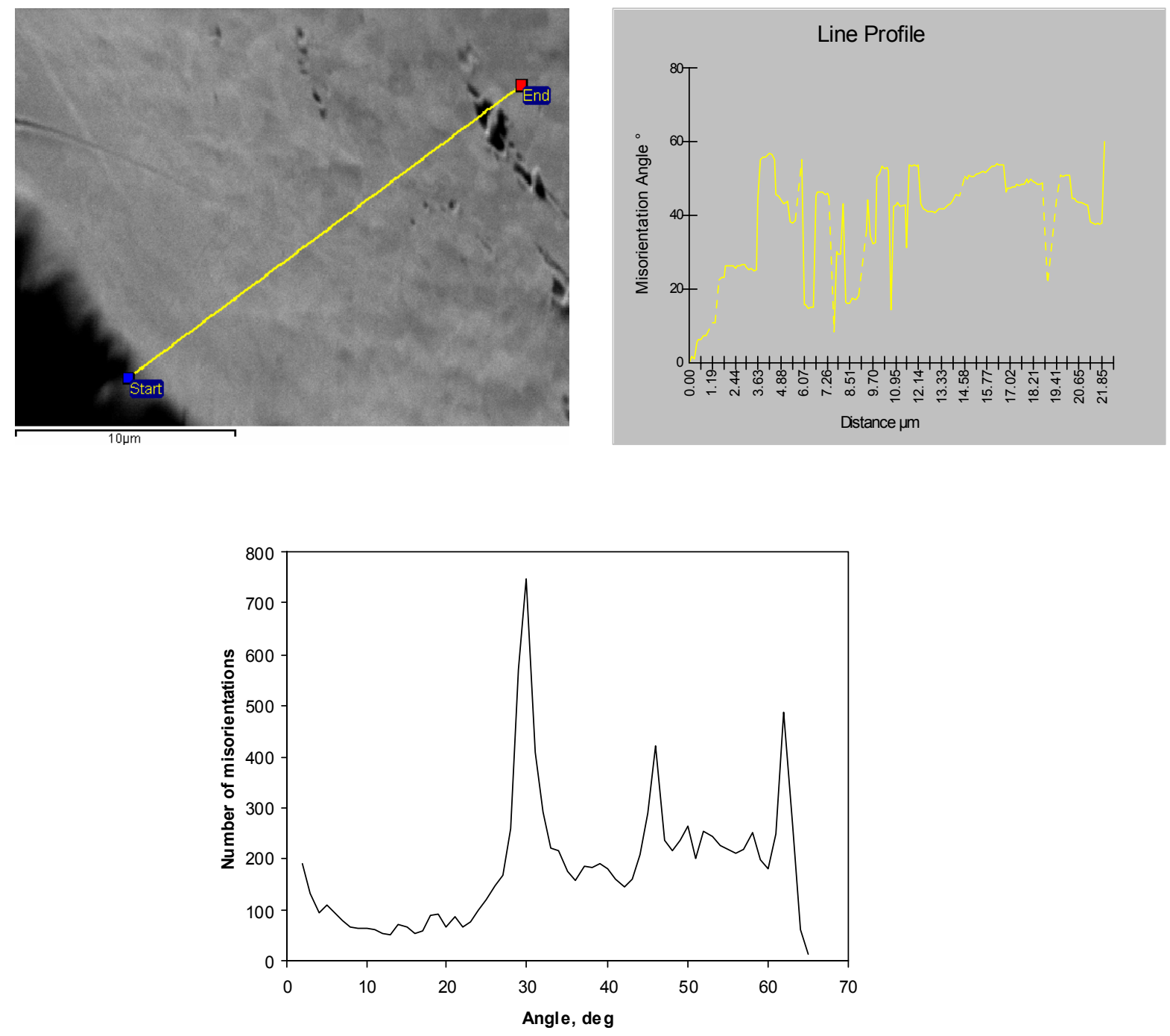
Figure(s)
Click here to download high resolution image

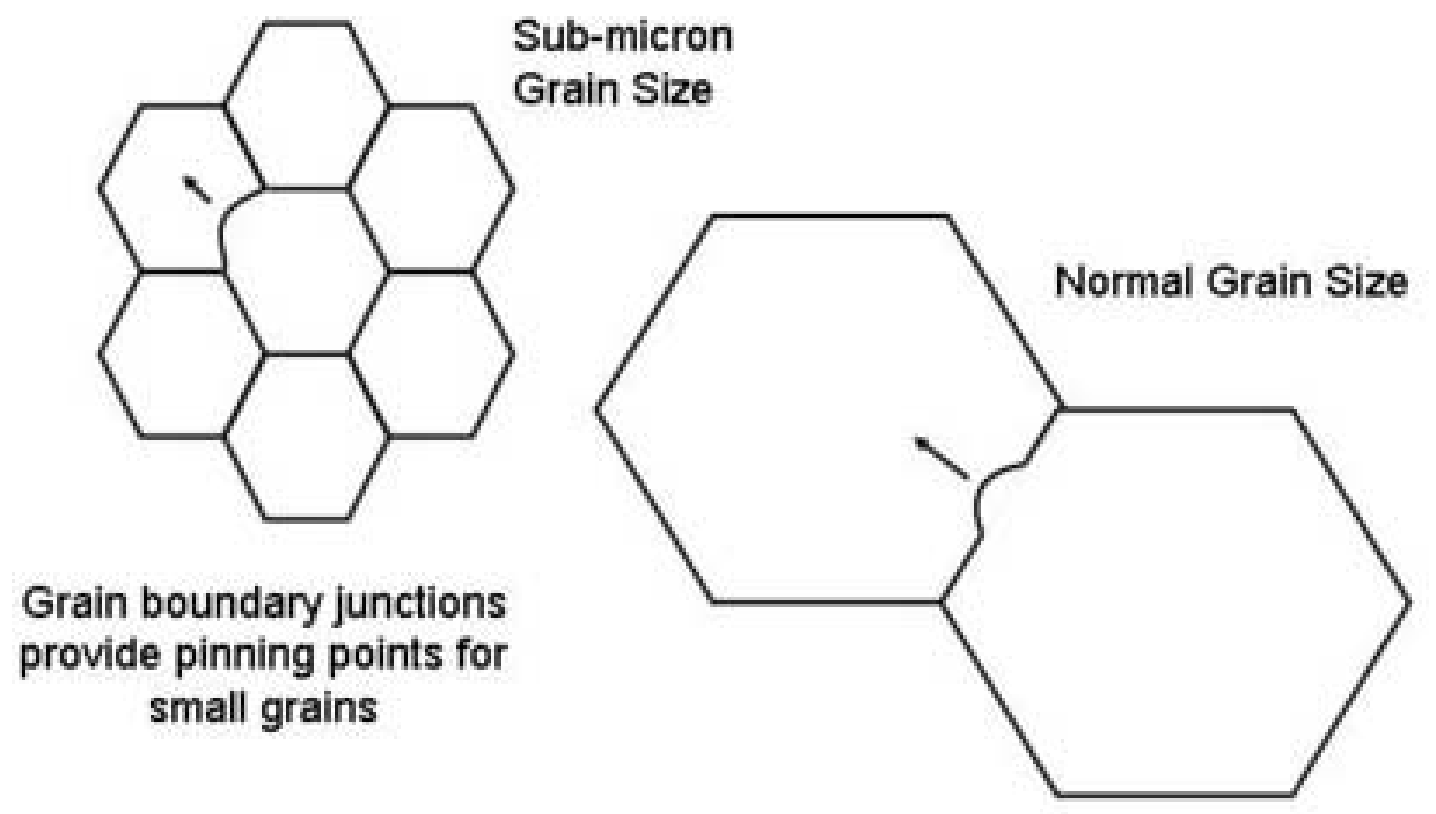


Figure(s)
Click here to download high resolution image

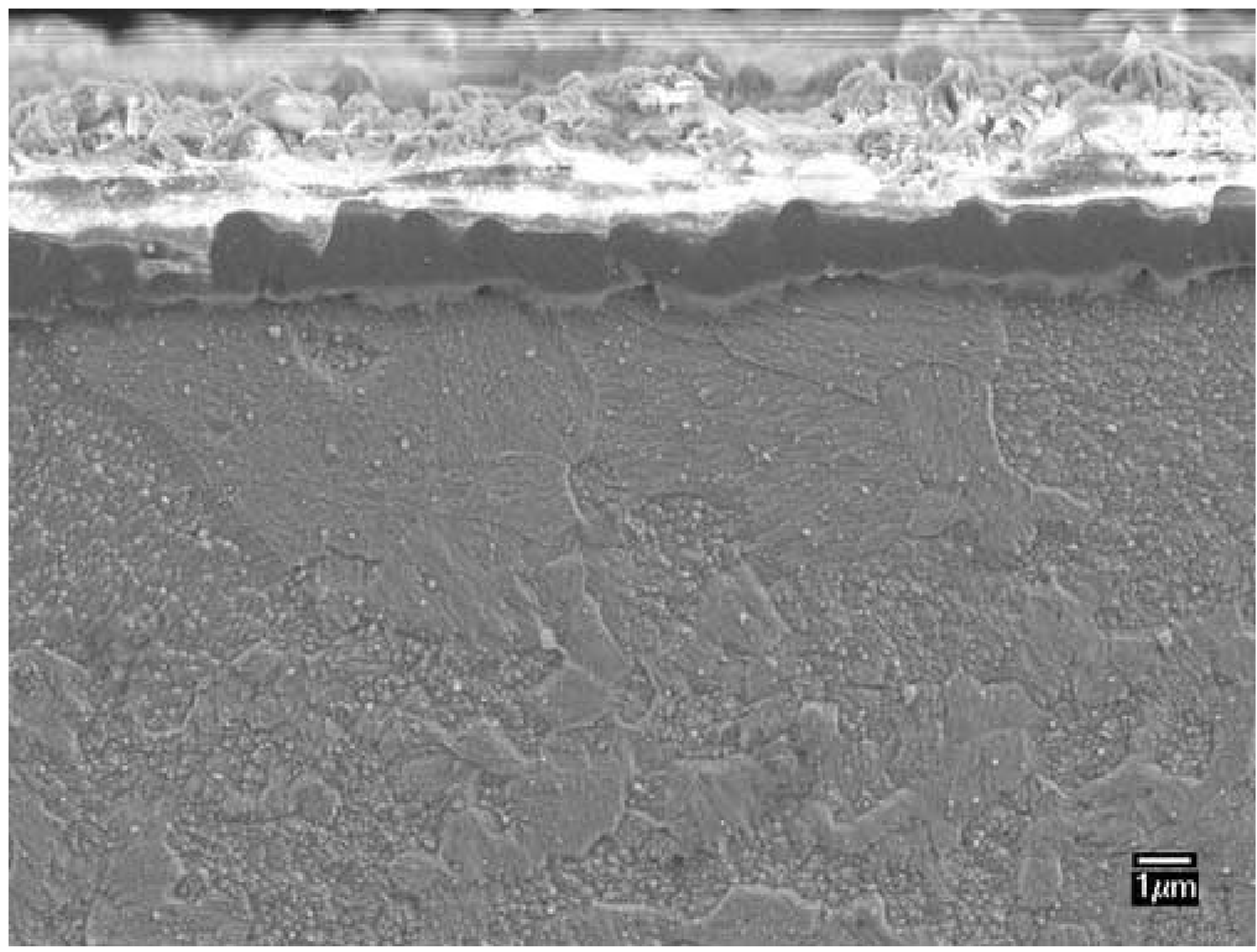


Figure(s)
Click here to download high resolution image

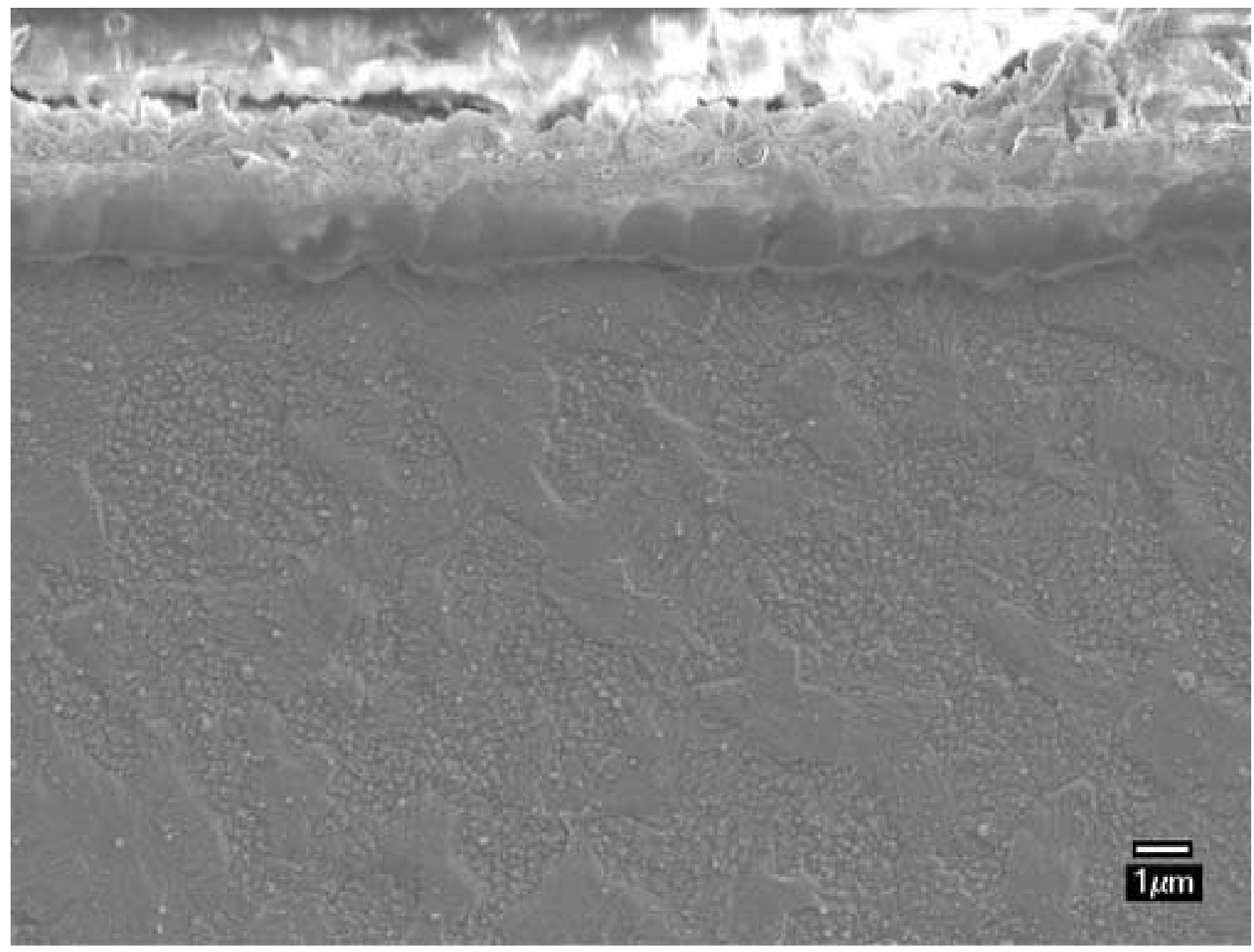

